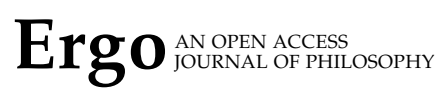

\title{
The Nature of Perceptual \\ EXPERTISE AND THE RATIONALITY OF CRITICISM
}

\author{
ERROL LORD \\ University of Pennsylvania
}

\begin{abstract}
If I say ... that the brandy is soft and velvety, and he questions what I say, it may not be enough merely to invite him to ... taste. I may need to draw attention to this and that... If he then finds himself agreeing with me, I have vindicated my claim in the best possible way, by getting him to see for himself. There is no reason not to say, if one wishes, that I have supported, justified, or even proved my original judgment. One might refer to this activity therefore as perceptual proof.
\end{abstract}

(Sibley 1965: 145)

T $\mathrm{T}$ borders on truistic that (paradigmatically rational) aesthetic judgments must be based on perceptual experience with the object that is judged. ${ }^{1}$ It is also plausible - although perhaps not truistic - that criticism is a rational enterprise.

Contact: Errol Lord <erlord@phil.upenn.edu>

1. Alas, while this is the claim on the most solid footing from which to begin, it is itself open to controversy and serious interpretation. The main issue is about the nature of aesthetic judgment. Some take aesthetic judgment to just be belief. If that is one's view of aesthetic judgment, then the first sentence of this paper is not truisitic (at least the nonparenthetical claim). Many-including me-think that we can have rational aesthetic beliefs that are not perceptual (for my take see Lord 2016; 2018a). Others-working mostly in the Kantian tradition-have a more conative/affective view of aesthetic judgment. The basic insight of these views is that aesthetic judgment involves appreciation (see, e.g., Gorodeisky 2010; Gorodeisky \& Marcus 2018). Given plausible claims about the rationality of appreciation, this view seems to predict that all rational aesthetic judgments are perceptual. In this paper I want to try to avoid 
Indeed, criticism appears to wear this on its sleeve. Critics appear to provide arguments for their critical conclusions. ${ }^{2}$

These two claims are famously in tension with each other. ${ }^{3}$ We can see this most clearly by drawing out what many take to be an implication of the truism. If rational aesthetic judgments must be based on perceptual experiences, then we cannot get rational aesthetic judgments via inference. After all, perceptual judgments are paradigmatically non-inferential. They are reactions to experiences that make the world manifest to us. Their justificatory power is not beholden to the justificatory status of any other states. ${ }^{4}$ This is one of the general powers of perception. Further, this seems to be of particular importance to rational aesthetic judgment. This is because token aesthetic properties are unique in a special way. ${ }^{5}$ Their instantiation is dependent on a very fragile configuration of features. Slight variations of an object's features can make or break it aesthetically. This is why perceptual access is important. It makes manifest the very particular way something is aesthetically.

If this is right, though, then it seems dubious that criticism is an ordinary argumentative activity. This is because ordinary argumentative activities present arguments that are inferential in structure. They invite the reader to infer conclusions from the considerations presented as reasons. Given the essential role of perception to the justification of aesthetic judgment, this sort of thinking doesn't seem to give us legitimate access to the aesthetic facts. Thus, it looks like criticism is rationally dubious.

One of the most important reactions to this tension-originally proposed by Isenberg (1949) and further developed by Sibley (1965) - maintains that a crucial role for the critic is to guide perception. The critic points to the non-aesthetic ways something is in order to guide consumers in seeing the work in the appropriate light. In this role the critic aims to make the aesthetic features of the work visible

this dispute about the best use of the term 'aesthetic judgment'. What I am interested in is the sort of cognitive state that is involved in appreciation-what, in other work, I call appreciative knowledge. It is truistic that this state has perceptual origins. I don't take this to settle whether we can have rational aesthetic beliefs that are non-perceptual.

2. One of the main philosophical debates about criticism is about its constitutive aim. Some (e.g., Carroll 2008) maintain that providing critical arguments is a constitutive aim of criticism. Many-e.g., Grant (2013), Cross (2017)—deny this. I make no claim here about whether providing arguments is constitutive (although I am largely sympathetic with Grant). The claim I need is that a certain rationalizing activity does take place in many critical texts. Grant, for one, agrees with this much. I want to understand how this activity could make sense given the role of perception in rationalizing aesthetic judgment.

3. For classic statements of the tension, see Isenberg (1949), Sibley (2001), Hampshire (1954). More recent discussion includes Dorsch (2013), Hopkins (2007a), Schellekens (2006), Shelley (2007), Cross (2017).

4. For articulations of this point, see Pryor (2000), Huemer (2001), Johnston (2006).

5. See, e.g., Levinson (1980). 
by making light of the non-aesthetic features that give rise to the aesthetic features.

While this thought on its own is very plausible, it doesn't by itself resolve the tension. Sibley infamously resolves the tension by holding that while critics aim to guide perception, the considerations they cite do not provide justification for their judgments. They merely provide an explanation for why they hold those judgments. Further, when the critic is right, she also provides an explanation of why the object in question has the aesthetic features that it in fact has.

On the other end of the spectrum, Dorsch (2013) resolves the tension by denying that non-inferential perceptual justification is central to the justification of aesthetic judgment. Instead, Dorsch suggests that justified aesthetic judgments are inferentially justified. They are justified by reasons provided by the nonaesthetic considerations that successful criticism cites.

This paper provides a middle path between these two extremes. It does this via what I take to be the best account of the metaphysics of aesthetic perception and perceptual expertise. According to this account-the Enrichment Account-we perceive aesthetic features only after we gain capacities that allow for aesthetic enrichment of the contents of our experiences. These capacities are a form of expertise, and they are triggered by perceptual experiences of the non-aesthetic features that the aesthetic features depend upon.

The structure and etiology of aesthetic perceptions have important epistemic consequences. Most importantly, their unique structure and etiology makes it plausible that they provide a sort of non-foundational direct access to the aesthetic features of things. The access is non-foundational because the rational power of the experiences is dependent upon the rational status of other states. The resulting justificatory structure is importantly similar to inferential justification (although, as we'll see, I don't think this is the best word to use). Nevertheless, the experiences do still provide direct access. They make the aesthetic world perceptually manifest. They thus provide access to unique aesthetic properties.

This allows us to dissolve our tension. Perceptual experience of aesthetic features can play an essential role in justified aesthetic judgment and criticism can be a rational activity. Critics really do elucidate the structure of their justification (at least the successful ones). This is because they elucidate the features that their justification epistemically depends upon. Further, this account gives an elegant explanation of how critics guide perception. They guide perception by pointing out the features the experience of which gives rise to the aesthetic enrichment of one's experience. Thus, perceptual guidance is a way of aiding the development of perceptual expertise.

My plan is this. In the next section I will further lay out the tension and the views that give rise to it. I will then, in Section 2, explicate what I take to be the best view of aesthetic perception. In Section 3 I will draw some important epistemic consequences of this view. Finally, in Section 4 I will argue that these 
consequences allow us to dissolve the tension between a perceptualist view of rational aesthetic judgment and critical practice.

\section{The Primacy of Perception and Critical Engagement}

\subsection{The Tension}

In this section I will flesh out my animating tension and the views that give rise to it. I will also explore the most prominent responses to the tension.

The idea that direct access is crucial for rational aesthetic judgment has been central to the epistemology of aesthetics since at least Kant. Indeed, this idea is central to the chief battle at the heart of contemporary aesthetics between so-called rationalists and what I will call perceptualists. ${ }^{6}$ Perceptualists like Kant and Hume argued against the rationalists by insisting that legitimate aesthetic judgments are immediate sensory judgments. ${ }^{7}$ This contrasts with the rationalist view that, at the very least, some legitimate aesthetic judgments are the result of mediated ways of thinking like inference. Frank Sibley, one of the most influential contemporary defenders of perceptualism, puts the idea by saying that 'aesthetic perception ... is essential to aesthetic judgment' (Sibley 2001: 40).

One of the driving ideas behind perceptualism is that there are no principles that link the aesthetic with the non-aesthetic. The rationalists hoped to provide a complete formalization of criticism analogous to the mathematical revolution that transformed physics. Perceptualists did not like this project, to put it mildly. This, to the perceptualist, is a complete perversion of aesthetic thinking. Kant polemically wrote 'If someone reads me his poem or takes me to a play that in the end fails to please my taste, then he can adduce Batteux or Lessing, or even older and more famous critics of taste, and adduce all the rules they established as proofs that his poem is beautiful ... . I will stop my ears, listen to no reasons and arguments, and would rather believe that those rules of the critics are false' (Kant 2000: 170). Less polemically, Sibley followed up the sentence quoted in the previous paragraph by writing 'one could not therefore be brought to make an aesthetic judgment simply as the outcome of considering reasons, however good'

6. Some use the term 'sentimentalist' (e.g., Shelley 2017). I'm avoiding that term because its most common usage refers to a group of metaphysical views that are importantly different from the view I am discussing.

7. I am, to be fair, ignoring some important aspects of both Kant and Hume's views. For one thing, neither thought that visual perceptual experience was the fundamental sort of aesthetic experience. For both a more conative state was key (see Gorodeisky \& Marcus 2018 for a state of the art Kantian view). More recent perceptualists like Sibley, Isenberg, and Walton have made visual perception (and the other sense modalities) central. What unites all of these views is the idea that perceptual experience broadly construed is necessary and indirect methods of thinking like inference are dubious. 
(Sibley 2001: 40).

For the perceptualist, then, we can have legitimate contact with the aesthetic only through our sensory faculties. However, many perceptualists (again, with Sibley being the paradigm), are clear that the sort of sensory contact we have with aesthetic features is importantly different than than ordinary perceptual contact. For Sibley, this is because contact with the aesthetic is enabled by a particular faculty-the faculty of taste. We use this faculty to have perceptual contact with the aesthetic. Further, since there are no true principles that link the aesthetic with the non-aesthetic, there is no mediated way to get legitimate access to the aesthetic. Thus, the only legitimate access we have is through sensory faculties.

Perceptualism is one half of the set of views that gives rise to our tension. The second half is provided by the view that criticism is a rational activity. By this I mean that the results of critical engagement-usually some text with a certain structure-can lay out considerations that bear on the rationality of the token activity the critic is engaged in. This way of putting it is very abstract. We can be more concrete once we assume that critical texts almost always have an argumentative structure. ${ }^{8}$ They have some sort of aesthetic evaluation that is the conclusion of reasoning. This is rational insofar as the premises of the reasoning bear rational relations to the conclusions.

This is already enough to cause a tension with perceptualism. For it looks like perceptualism is incompatible with there being any sort of rationalizations of aesthetic judgments that have an argumentative structure. If there were, then it seems like we could get rational aesthetic judgments via inference from the premises that critics cite. This would allow us to learn about the aesthetic features of things we have never perceptually interacted with simply by reading criticism.

This is pretty bad, but it gets even worse. This is because the premises that critics often appeal to are just about the non-aesthetic features of the objects of evaluation. Here are some examples. ${ }^{9}$

First, here is Emily Nussbaum (a TV critic for The New Yorker) writing about

8. Although I think it is clear that critical texts have a certain structure that can rightfully be called argumentative, I will remain neutral about whether they contain proper arguments. This is a delicate issue in aesthetics and, as we just saw, part of what has driven our motivating tension. Many hold that arguments require principles, and, as I just said, there is deep skepticism about aesthetic principles (this goes back to Isenberg 1949; see Shelley 2007 for a nice presentation of some of the details; for a powerful antidote to orthodoxy, see Cavedon-Taylor 2017). For my purposes, it is enough that critical texts provide reasons for critical conclusions. This is enough for criticism to seem like a rational activity. For ease of expression, however, I will continue to refer to them as arguments.

9. I include these examples and my discussion of them because I think that the literature could use an infusion of serious engagement with actual critical arguments (and, as a matter of historical fact, it seems to me that those who have done this have skewed more towards the truth). If you don't care to see the examples or they become tedious to you, you can safely skip ahead to page 817 . 
an episode of HBO's High Maintenance:

"Globo" lasts just twenty-six minutes. And yet, somehow, in its spiky, elliptical, warmly observant way, as the camera floats without judgment from one thread to another, from bistro to crash pad to brownstone stoop-sometimes following the Guy as he delivers weed to customers, but just as often not-it manages to suggest an entire city looking for comfort. A fat man struggles to maintain his workout regimen, but each time he tries to post his progress on Facebook he sees someone grieving and deletes the draft. A woman and two bros hook up at the McCarren Hotel, a decadent bubble far from the headlines. An exhausted immigrant waiter takes a long subway ride. Each plot gets an O. Henry twist, one funny, one filthy, one sweet. It never feels contrived, because the stories seem spontaneous, as natural as a train of thought. It's a remarkable achievement of narrative efficiency, fuelled by humility. (Nussbaum 2018)

Nussbaum's evaluative conclusion is that the episode is 'a remarkable achievement of narrative efficiency, fuelled by humility'. This conclusion is supported by a bit of reasoning about the way in which the episode is constructed. To be sure, the reasoning is complicated and there are several preliminary aesthetic conclusions-for example, that the narrative never feels contrived. Nevertheless, the premises of the reasoning all focus on non-aesthetic features, most prominently that the short scenes manage 'to suggest an entire city looking for comfort'. In short, Nussbaum argues that the episode has a particular aesthetic feature-being a remarkable achievement of narrative efficiency-on the grounds that it succinctly captures the way in which the city is looking for comfort.

A literary example comes from Cathleen Schine's discussion of Michael Chabon's Telegraph Avenue:

Chabon is one of those writers who cherishes his characters. They are all his imaginary friends, still in the attic. And he is not afraid to venture into their alternative universes, even those as close as Telegraph Avenue. He views the battered world of the border between Oakland and Berkeley with the same loving, infatuated scrutiny that science fiction bestows on its vast galaxies, and the battered borderland is the better for it. Chabon delights in the way the world could be. He is filled with nostalgia for a way it never really was. In Telegraph Avenue, those impulses come together and somehow manage to illuminate the way the world really is in all its tender, flawed glory. (Schine 2012)

Once again, this presents a sort of argument (or perhaps more than one argument). Although it isn't put exactly this way, it's plausible to take the conclusion to be 
that the novel is realistic-it 'illuminate[s] the way the world really is in all its tender, flawed glory' - in an aesthetically good way. This conclusion is supported by reasons. The book, in Schine's view, displays a sort of love for characters and setting that, when combined with a longing for what could be, ends up being a mirror onto the world. It seems implied by the context that the aesthetic value of this realism is heightened by the fact that Chabon is interacting with a genre-science fiction-that is defined by non-realism (although, of course, at its best it is realistic in precisely the way Schine thinks Chabon's book is).

Schine's main premises here are non-aesthetic. Chabon's love for his characters and his setting is not itself an aesthetic feature. Nor is the nostalgia expressed. But when those non-aesthetic features are put together in just the right way, you get the aesthetic feature Schine wants to draw our attention to. ${ }^{10}$

One final example comes from Michael Fried's book-length treatment of Caravaggio. Fried provides many detailed descriptions of many of Caravaggio's paintings. The implicit goal of most of these descriptions is to show just why Caravaggio's works have certain aesthetic features. Indeed, usually the conclusion of the arguments are themselves implicit or only provided later. ${ }^{11}$ I will provide one example, which requires some set-up.

One of Fried's main points about Caravaggio is that he was often interested in portraying two different relationships the artist can have with their works. On the one hand, there is the relation of creating the work, which Fried often calls the immersive relation. The second relation is the specular relation, which is the relation the artist has to their work as a spectator or consumer of the work. Fried argues that in many paintings Caravaggio seeks to visually portray these relations, which are often in tension with one another (those familiar with his Boy Bitten By a Lizard can recognize how the boy's facial expression might portray the horror of becoming a mere spectator).

Fried argues that Rest on the Flight seeks to portray these two relations. After giving a detailed description intended to show that the painting portrays the immersive relation, he says this: ${ }^{12}$

10. An alternative way of interpreting the argument is that Schine, much like Fried below, is trying to establish that Chabon's book is good (or has some other 'thin' aesthetic feature). The final premise of the argument, on this reading, is that Chabon's book is realistic in the relevant way. The rest of the argument stays the same. One reason to prefer this interpretation is that it allows one to think that being realistic is not itself an aesthetic feature. Of course, to interpret the argument in that way for that reason is just grist for my mill, here.

11. In a summary of the argument I will discuss that appears in the next chapter, he says 'As my account of the Musicians and the Rest on the Flight made clear, I take those pictures ... to have been a brilliant and influential invention on Caravaggio's part' (Fried 2010: 141).

12. The quote I provide focuses heavily on some of the aesthetic features of the work. This is somewhat unfortunate given my aims. However, one cannot read the whole argument summarized here without recognizing that Fried thinks the interesting aesthetic features are to be explained by appealing to the non-aesthetic features. What comes before the passage 
In other words, I see the spatial structure of this most poetic of paintings as expressing the 'lived' spatiality of its maker in the act of making-or perhaps I should say the 'lived' spatiality of its maker as he was immersed in the act of making. At the same time, there are features of the painting that powerfully counter the effect of identification and surrogacy, none more powerfully than the epicene beauty of the youthful angel, the ravishingly painted drapery that barely caresses the otherwise naked body it encircles, and the magnificent, almost disturbingly authentic avian wings ... Angel, drapery, and wings combine to separate and distance the viewer from the painting, or to put this more strongly, in the Rest on the Flight the conspicuous beauty and refinement both of that central figure and of the painting's meticulous but ever-fresh-seeming execution perform the work of specularization. (Fried 2010: 130-131)

Fried's argument, then, is that the work is great because it simultaneously portrays these two relationships that an artist can have to their work. He argues in this passage that the painting portrays the specular relation because the 'angel, drapery, and wings combine to separate and distance the viewer from the painting,' which, in this case, is the portrayal of specularity. This conclusion is a premise in his larger argument. The key move is to claim that the combination of this premise with the sub-conclusion that the painting portrays the immersive relation explains the 'brilliance' of the painting. ${ }^{13}$

These examples are representative of much critical activity. The important point is that critics appeal to reasons to draw certain conclusions about the aesthetic features of the works they are engaging with. Further, often these reasons are provided by non-aesthetic facts. Indeed, it is plausible that the nonaesthetic features enjoy a sort of fundamentality in critical argument. One might appeal to contributory aesthetic features to some extent, but complete critical arguments must ultimately bottom out in claims about the way in which a work is non-aesthetically. ${ }^{14}$

quoted is a very long description of the non-aesthetic features. Indeed, the portrayal of the two relations is a non-aesthetic feature. Fried claims that the painting is great in virtue of having this non-aesthetic feature.

13. While this example is a bit involved, I think it's important to include an example of criticism that is allowed to breathe, as it were. The other two examples are criticism, but they are also journalism. They don't have the space to fully make their case, and they are not explicitly couched in terms of arguments. More academic criticism, which I take Fried to exemplify, lack those features. This is important to point out for my purposes.

14. This must be true if the aesthetic is deterimned by the non-aesthetic. This is the orthodox view in the metaphysics of aesthetics, made explicit and famous by Sibley (2001). Even if the aesthetic isn't necessarily determined by the non-aesthetic, it is still plausible that usually there is a tight relation. This would be enough to make intelligible critical practice. See, e.g., Lamarque (2010), Currie (1990) for more discussion of the metaphysical issues. 
From the perceptualist's perspective, this activity must lack a certain sort of rational pedigree. In fact, it looks like the activity contravenes both of perceptualism's main commitments. First, recall that the perceptualist denies that there are any principles linking the aesthetic to the non-aesthetic. Critical arguments appear to rely on such principles. After all, critical arguments seem to implicitly assume that there is some relation between the aesthetic and the non-aesthetic that one can licitly appeal to in critical argument. So critical arguments are in tension with the perceptualist's negative commitment about inference.

They are also in tension with the perceptualist's positive commitment that the only legitimate method for forming aesthetic judgments is perceptual. After all, arguments are the sorts of things one offers as a means to persuade someone to accept one's view. Successful arguments are the sorts of things we can use to extend our rational beliefs. The perceptualist denies this view for aesthetic thinking. Thus, perceptualism is committed to thinking that critical arguments cannot be a source of legitimate aesthetic judgments.

This tension is troubling even for the die hard perceptualist. For starters, it seems to condemn critical practice to serious error. Just as it is difficult to conclude that mathematical practice is dubious in light of the philosophy of mathematics, it is difficult to conclude that art critical practice is dubious in light of philosophical aesthetics. The critics probably have a better handle on their practice than the philosophers, so the philosophers should be loath to pronounce criticism rationally bankrupt. Secondly, even if you are willing to draw this conclusion, you still have the burden of explaining why criticism has something going for it.

\subsection{Reactions to the Tension}

Now let's briefly explore some of the extant reactions to the tension. We will start at the extremes. First, one can dig one's perceptualist's heels in. To do this is to insist that critical arguments lack the epistemic power to rationalize aesthetic judgment. On this extreme we find Sibley (and Isenberg 1949). Sibley sticks to pure perceptualism even in light of the tension. Now, this is not to say that he doesn't have some rationale for critical practice. He thinks that critical arguments play at least three important roles. First, they elucidate the psychology of the critic. That is, they lay out the considerations that, at least posterior to experience with the object, the critic takes to support the critical conclusion. Second, and relatedly, critical arguments attempt to elucidate metaphysical explanations. They point to features that the critics maintain metaphysically ground the aesthetic features. Successful criticism provides successful metaphysical explanations. Finally, and perhaps most importantly, Sibley maintains that critical arguments aim to guide the perception of the consumer. That is, they attempt to draw the consumer's attention to the features of the work that give rise to the aesthetic features. This 
third role is crucial to providing an explanation of why it is that critical arguments are addressed to their particular audience. This is needed since Sibley maintains that the usual reason why arguments are directed at a certain group-to rationally persuade-is moot in the case of criticism.

Most participants in the literature agree with Sibley's last point-that is, that one aim of criticism is to guide perception. However, Sibley's combination of views does more to bring out the oddity of this extreme than to demystify it. Think of it this way: Sibley maintains that successful criticism presents correct metaphysical explanations for why the objects in question have the aesthetic features they have. These explanations provide a full metaphysical account of the aesthetic features. Further, honest critics, on Sibley's view, elucidate why they hold the aesthetic judgments they do by appealing to the explanans in these metaphysical explanations. Yet, despite this, Sibley maintains that the explanans of these explanations cannot rationalize the conclusion either for the consumer or the critic. So the successful critic, on Sibley's view, has in hand a successful metaphysical explanation, the explanans of which are the reasons why the critic holds the view she does, yet those considerations go no way towards rationalizing her judgment. This is very odd.

Sibley sides with philosophy over critical practice, as it were. On the other extreme we have the view that digs in its critical heels. On this view, which is defended most explicitly in Dorsch (2013), we have to give up perceptualism because we need to fully vindicate critical practice. Dorsch maintains that this requires holding that aesthetic justification is fully inferential. This doesn't entail the psychological claim that each aesthetic judgment is formed in an explicitly inferential way; subconscious inference is possible and potentially ubiquitous. But it does mean that aesthetic justification has an inferential structure; the justified claims are only so justified because they bear certain relations to other justified claims. This is exactly the sort of claim that perceptualists deny in response to rationalism. Dorsch accepts it because he thinks it is the only way to fully vindicate critical practice. Criticism is a rational activity, on Dorsch's view, because critical arguments elucidate arguments that justify at least the critic.

Those are the extremes. Unsurprisingly, we also find philosophers trying to carve out a path in the middle. One middle path can be found in Hopkins (2007a). The hypothesis that Hopkins considers (although he doesn't really endorse) is that perceptual experiences themselves can be the conclusion of inference..$^{15}$ If this were right, then critical arguments could spell out the premises that the critics' perceptual experience was inferred from. Further, if you hold that with inference

15. In another context Siegel (2017) provides comprehensive arguments for this claim. Although I end up agreeing with the spirit of Hopkins's view, I don't think the psychological claim that it is anchored in is plausible. I spell out some reasons why in reply to Siegel in Lord (in press). 
comes justification, you can also maintain that the critical argument spells out the justification for one's perception. Finally, if you hold that one's aesthetic judgment is based on one's perception and that the justificatory relation is transitive, then you get that the critical argument spells out the justification of one's judgment. This is compatible with perceptualism since it still might be that the only way that one can have a justified aesthetic judgment is by having perceptual contact with the object in question. Thus, on this view, critical arguments elucidate asymmetric justifications-justifications for the critic's judgment that are incapable of justifying the consumer's judgment. ${ }^{16}$

In what follows I am going to defend a new middle path. On the one hand, I will argue that the structure of paradigmatic justification of aesthetic judgments is non-foundational. In this I agree with Dorsch and Hopkins. However, this does not mean that such justification is not perceptual and thus that the psychological processes that lead to aesthetic judgments are not non-inferential. This is why Dorsch and Hopkins's views fail (although for different reasons). The key to seeing why both of these views are true lies in the nature of aesthetic perception. I will draw on more general considerations in the philosophy of mind to argue that aesthetic perception belongs to a class of perception that provides nonfoundational perceptual access. The upshot will be that we can explain why it is that critics are elucidating their justification within a strict perceptualist framework. Further, my view about the metaphysics of perception provides both an elegant explanation of the way in which critics can guide perception and an elegant way to understand the distinctive role of taste in aesthetic perception.

\section{Enriched Content, Perceptual Expertise, and Aesthetic Perception}

It is common sense that we perceive aesthetic properties-we can see and hear beauty, grace, vividness, garishness, gaudiness, and kitcshiness. It is also well entrenched in aesthetics. ${ }^{17}$ Indeed, a popular account of what it takes to be aesthetic appeals to perceptibility. ${ }^{18}$ Despite that, relatively little work has been done working out the mechanics of aesthetic perception. As it turns out, this is a major oversight, for much recent work in the philosophy of perception shows that it is far from obvious that aesthetic properties can feature in the content of perceptual experiences.

To see this we should draw a distinction between two different kinds of

16. There are, of course, other possibilities. For example, Schellekens (2006) argues that critical arguments can elucidate legitimate justifications, but only after one forms the perceptual judgment. Thus, on her view, the justification is not only asymetric between the critic and consumer, it is also asymetric with respect to different time slices of the critic.

17. See, e.g., Sibley (1965), Binkley (1977), Carroll (2001), Levinson (2001), Shelley (2003).

18. See Shelley (2003) and citations therein. 
perceptual content. On the one hand, there is low-level content. ${ }^{19}$ When focusing on vision (which I will do henceforth), this is content having to do with colors, edge properties, and spatial relations. Everyone agrees that perceptual experiences have low-level content. Representing low-level content is an essential function of such states.

On the other hand, there is high-level content. This is any other content one might think perceptual experiences have. For example, artifactual kind content having to do with tables, mirrors, computers or natural kind content having to do with tigers, human beings, or gold. If you think that we can have perceptual experiences that have as part of their content tables or human beings or gold, then you think that perceptual experiences can have high-level content. Aesthetic content, if it exists, is high-level content. Thus, in order to defend aesthetic perception, one must defend the existence of high-level content. The rub, of course, is that it is controversial whether there is high-level content. ${ }^{20}$

Controversial but, I think, very much defensible. The goal of this section is to sketch what I take to be the best account of aesthetic perception. This account is part of a more general view that explains (at least some) high-level content. I won't offer a full defense, but that is not necessary for my main goal, which is to show that we can dissolve our tension by adopting this view. ${ }^{21}$

Let's start with a prominent example of high-level content. ${ }^{22}$

\section{The Arborist}

Kathy is a budding arborist who is tasked with the job of tagging every pine tree in a particular forest over the course of a summer. At the beginning of the summer she has to use inference to figure out which trees are pine

19. I will talk of both low/high-level content and low/high-level features. The latter are just the features that the former aim to pick out. Although I will speak of content to make the prose a bit easier to manage, I don't intend to take a stance about what the objects of perceptual experience are. That is, I remain neutral about whether the objects are representational contents or, at least in the case of perceiving, the worldly items in the scene.

20. See Macpherson (2011), Helton (2016) for some nice overviews.

21. Nanay (2016) argues that we lack the resources for establishing that aesthetic properties can figure in the contents of perceptual experiences. Instead, he argues that we should switch to discussing aesthetically relevant properties. Some of these properties clearly can figure in the content of perceptual experience (although, of course, the only ones that clearly do are the low-level ones; anything beyond that is controversial). In other work I argue, pace Nanay, that we do have the resources for establishing that aesthetic properties figure into perceptual content. This is not of primary importance here since I am only arguing for the conditional conclusion that if aesthetic perception has the structure elucidated below, then we have a solution to our puzzle about criticism. Further, I think the view of perception I defend does give a prominent place to Nanay's aesthetically relevant properties. Because of this, I think my view can do a lot of the work he wants to do in Nanay (2016).

22. A version of this case was originally presented in Siegel (2006) and is one of the main cases in Siegel (2010). 
trees by looking for certain characteristic low-level properties and inferring that there is a pine from those features. However, over time this changes so that she immediately recognize the pines as pines. Kathy's experiences change over the course of the summer. At the end of the summer the phenomenology of her experiences with the forest is different than it was at the beginning.

First focus on Kathy at the beginning of the summer. At that time she has all that is needed to perceive the low-level features that correlate with pine-ness. I will call these features the Corresponding Features. In the case of pine trees, the main corresponding feature is that the needles are clustered (as opposed to being attached directly to the branch individually). At the beginning of the summer Kathy has perceptual experiences that represent the needles of the pines as being clustered. But the best she can do with that information is form a belief that they are clustered and then infer from that belief that the tree in question is a pine. What she gains over the course of the summer is the ability to have perceptual experiences with additional content. This is the high-level content of pine-ness. By the end of the summer she has gained an ability that enriches her perceptual experience with pine-ness.

This newly gained ability is not brute. It is not as if there is no explanation for how Kathy went from the abilities she had at the beginning of the summer to the abilities she has at the end. ${ }^{23}$ Further (and this is crucial for what is it follow), it is not as if there is simply no connection between her representation of the high-level properties and her perceptual representation of the corresponding features. There is a tight connection between the two. It is not plausible that her representation of the high-level content manifests absent a representation of the corresponding features. Rather, her previous inferential ability seems to have been integrated into her perceptual capacities themselves. Nevertheless, the new perceptual ability she gains is dependent upon her representation of the corresponding features. ${ }^{24}$

23. Some-e.g., Connolly (2014)—argue that Kathy had the recognitional ability all along. On this line, Kathy had the ability in virtue of the fact that it was possible for her to 'flail' into the appropriate state before she gains expertise. Expertise, on this view, consists in skills rather than abilities. The skills consist in a reliable way of triggering the abilities (roughly). This poses some dialectical problems for certain arguments for enriched high-level content, but I don't think it poses serious problems for the schematic account I provide. At worst, I'll need to talk about skills rather than abilities.

24. While this seems to me an important assumption in many discussions of high-level content, it is hard to find it explicitly mentioned. Siegel mentions it and seems to endorse it in Byrne and Siegel (2017). She writes, 'if one comes to perceive [high-level] properties ... plausibly one does so in part by perceiving the [low-level] properties ... For instance, if watching a softball game leads one to think that the batter's swing sent the ball flying, one attributes causal efficacy to the bat (and to the batter) in part by seeing their position relative 
So, in the case of at least some high-level content, it looks like the mechanics contain two important parts. First, we need an explanation of how we acquired the new perceptual ability, and a story about what constitutes this ability. Second, we need an explanation of the connection between the representation of the highlevel features and the representation of the corresponding features. Once we have both parts, we'll have an explanation of what I'll call enriched high-level content.

Here is a schema for what we need in an adequate theory of the mechanics of enriched high-level perception. First off, we need to posit the ability, which we can understand as being grounded by a state that facilitates the enrichment of the experience with high-level content. Call this the Enrichment State. Second, we need to connect the Enrichment State with the perception of the corresponding features. The most natural way to do this, I think, is to hold that experience of the low-level features is an input into the Enrichment State. The Enrichment State then outputs the enriched content. An adequately fleshed out instantiation of this schema explains the unique mechanics of enriched high-level perception. The Enrichment State is what is gained through learning. Further, the high-level content is related to the corresponding features because the enrichment of the content depends on the experience of the corresponding features.

To be clear, I am not claiming that all high-level content must come about via mechanics with this form. It might be that there is some high-level content that is not dependent on either an enrichment state or on perceptual experiences of corresponding features. ${ }^{25}$ In the case of low-level content, however, things are different. Most importantly, there simply are no corresponding features. The low-level features are perceptible in a more basic way. We don't need to perceive something else in order to perceive the low-level features. ${ }^{26}$ So, for all I say, it could be that we have recognitional capacities for some high-level content

to the ball, their shape, and one saw those things in part by seeing the illumination and color contrast of those items' (Byrne \& Siegel 2017: 60). See also Audi (2013) (although it is not entirely clear there if Audi is thinking of high-level content in the sense that Siegel and I are).

25. This leaves open that there are other forms of high-level content. Most obviously, it leaves open that there is some high-level content that is not dependent on perceptually experiencing the low-level content. Nanay (2012) discusses cases that, he argues, are like this (although he doesn't put it that way).

David Davies pointed out to me that the auditory perception of semantic meaning is plausibly also like this. Once we learn a language, it's not clear we still have auditory perceptual experiences of the auditory corresponding features-that is, we don't have auditory experiences of the sounds that non-speakers of the language have. Rather, it seems like we just experience the meaning directly (of course we still process the corresponding features, but we don't have an experience that represents both these features and the meaning).

26. Of course, a complete theory of perception is going to tell us what explains or constitutes the perceptual ability to perceive the low-level features. However, in the normal case, it doesn't look like these are abilities that we acquire through learning. It looks like our perceptual systems come with these abilities built in. So, in the normal case, there won't be any need to explain how we learn to perceive the low-level features. 
that works like our recognitional capacities for low-level content. The content is derived from pre-perceptual information. This high-level content would not be dependent on perceptually experiencing other content in the way that enriched high-level content is.

Even though this sort of high-level content is not ruled out by what I'm claiming, it's not particularly plausible that high-level aesthetic content is like this. If it were, then it would be possible to perceive aesthetic features without perceptually experiencing at least some of the corresponding features-that is, without having perceptual experiences representing any of the non-aesthetic features of the object that correspond with the aesthetic features. So, for example, if this view were true for all aesthetic perception, it would follow that one could perceive the intensity of Manet's Olympia without perceptually experiencing the non-aesthetic features of the women's gazes that makes the painting intense. This is compatible with having some sort of perceptual input, but this input would have to be pre-experiential. It would have to be, in other words, that you lack a perceptual experience-the kind of state that represents those features and can be accurate or inaccurate- of those features.

To get a better feel of what this might be like, consider a particular kind of chicken-sexer. Chicken-sexers have the ability to reliably distinguish the sexes of very young chicks. What is odd about chicken-sexers is that they don't know how they do this. They cannot tell you which features they pick up on that allow them to reliably distinguish the sexes. One potential way that someone could gain this ability is by having a capacity to represent sexes in perceptual experience that is only sensitive to pre-experiential information. ${ }^{27}$ In this way, the chicken-sexer's ability to represent sexes is like an ordinary ability to represent colors. One cannot tell you why their experience represents color by telling you the information in virtue of which one's perceptual system comes to represent that particular color. This is plausibly because the information that informs one's perceptual system is pre-experiential when it comes to colors. Something similar could be going on with chicken-sexers. It could be that there is pre-experiential information that informs the perceptual system so that it represents the sex. This would be high-level content that does not depend on perceptually experiencing the corresponding features.

This much seems true: This is not how it usually works with aesthetic perception. Although we not might always be able to quickly articulate which non-aesthetic features contribute to the aesthetic features we perceptually experience, it is still the case that those non-aesthetic features are represented by our experience. The colors, shapes, lines, spatial relations are all there at the level

27. I am not claiming that this is the correct explanation of what happens with actual chicken-sexers. But it is one possible explanation that does account for some of the peculiarities of chicken-sexing. 
of our perceptual experience. Aesthetic perception analogous to pre-experiential chicken-sexer perception would seem like magic. It would be the ability to perceive the intensity of the painting without seeing the colors, lines, and spatial relations. That would be utterly bizarre.

So, the modest conclusion is that even if it's possible for there to be high-level content without enrichment, the paradigm of aesthetic perception is enriched high-level perception. If this is right, then we need to fill in this mechanical schema in order to vindicate aesthetic perception. No matter what else is said, in order to vindicate high-level aesthetic content, one needs to tell us a story about the Enrichment State and about how this state is related to the perceptions of the corresponding features. As we proceed I will say some things about which types of things can play the role of the Enrichment State. As we'll see, most of the discussion of the epistemic justification gained from enriched high-level perception has been about the Enrichment State. This discussion is important and I will discuss it in the next section. However, this is not what I will rely on the most. Instead, I think that the serious controversy garnered by discussions of the Enrichment State can be sidestepped by focusing on the relationship between enriched high-level content and experiences of the corresponding features. By focusing on this, we can see that high-level experiences fail to provide foundational justification no matter what we say about the Enrichment State.

\section{The Epistemological Consequences of the Structure of Aesthetic Perception}

While the Enrichment Account vindicates aesthetic perception, it does so by complicating the structure of perceptual experience. This section draws out some of the epistemic consequences of this structure. My main claim is that aesthetic perception does not provide foundational justification. This is because the rational power of aesthetic perception is dependent on the rational status of other states. ${ }^{28}$

Let's start with two epistemic distinctions. First, the distinction between foundational and non-foundational justification. If one's belief that $p$ is foundationally justified, then its justification does not depend on one being justified in believing something else. Non-foundational justification is not like this. For example, if one is justified in believing $q$ because one is justified in believing $p$ and if $p$, then $q$, then one's justification for believing $q$ is non-foundational-it depends on one's justification for $p$ and if $p, q$.

The second distinction is the distinction between ex post and ex ante justification. ${ }^{29}$ When one is ex post justified in believing $p$, one has a token belief that $p$

28. For a longer defense of the claim that the justification provided by enriched high-level content is not foundational, see my Lord (2019).

29. This distinction is sometimes drawn using the terminology 'propositional' versus 
that is justified. When one is merely ex ante justified, one is in a position to have a token belief that is justified, but needn't actually have one. So, for example, one might be ex ante justified to believe $p$ after perceptually experiencing $p$ even though one doesn't actually believe $p$. In a different sort of case, one might be $e x$ ante justified to believe $q$ because one is ex ante justified to believe $p$ and if $p$, then $q$ but fail to have an ex post justified belief that $q$ because one does not believe $q$ for $p$ and if $p$, then $q .{ }^{30}$

Recall that there are two parts to enrichment. First, there are enrichment states that link low-level features with high-level features. Second, there is the experience of the low-level features. There has been an enormous amount of discussion of the epistemic consequences of the etiological role played by enrichment states. ${ }^{31}$ For at least some enrichment states, it is very plausible that the justification provided by enriched experiences is dependent on those states and is thus non-foundational..$^{22}$

To take an aesthetic case, consider Walton's (1970) Guernica example. First consider Picasso's Guernica as it is in the actual world. Walton makes the plausible claim that Picasso's Guernica is a 'violent, dynamic, vital, disturbing' painting. Now imagine a merely possible world where there is no category PAINTING. Despite this, they do have the category GuERnICAs. A crucial difference between the categories is that where the surfaces of paintings are paradigmatically flat, the surfaces of guernicas are paradigmatically three-dimensional. As Walton describes it,

All of them are surfaces with the colors and shapes of Picasso's "Guernica," but the surfaces are molded to protrude from the wall like relief maps of different kinds of terrain. Some guernicas have rolling surfaces, others are sharp and jagged, still others contain several relatively flat planes at various angles to each other, and so forth. (1970: 347).

Now suppose consumers of guernicas come into contact with an object qualitatively identical to Picasso's Guernica. They would naturally take it to be a guernica. It is non-paradigmatic in virtue of its flatness, but it is a guernica nonetheless. However, their judgment of the aesthetic features of that object would be radically different qua guernica than our judgments are of it qua painting. Critics in the guernica world, claims Walton, would see it as 'cold, stark, lifeless, or serene and restful, or perhaps bland, dull, boring-but in any case not violent, dynamic, and vital' (1970: 347). Further, it is plausible that they would be right to so judge, just as actual critics are right to judge Picasso's piece as violent qua painting.

'doxastic' justification.

30. For much more on this distinction, see Lord (2018b).

31. See, e.g., Siegel (2012; 2017), Silins (2013), McGrath (2013).

32. See especially Siegel (2017). 
As Stokes (2014) argues (and Walton asserts), one can plausibly explain this difference in terms of differences in perceptual experience. Consumers of guernicas in the merely possible world perceive Picasso's piece (or the object qualitatively identical to it) as serene and restful, whereas consumers of paintings in the actual world perceive Picasso's piece as violent and dynamic. What accounts for the difference is their background beliefs about the different categories, and, in particular, background beliefs about paradigmatic surface features. These background beliefs partly constitute the enrichment states of the experiences that represent serenity, restfulness, violence, dynamism (etc.). ${ }^{33}$

Thus, reflection on Walton's example suggests that one's enriched perception of Picasso's Guernica is causally dependent on one's background beliefs about the category PAINTING. It also seems plausible that the justification provided by the perception of the dynamism (e.g.) is epistemically dependent on the justificatory status of those background beliefs. ${ }^{34}$

This is perhaps easiest to see by thinking of cases where one's enriched perception is non-veridical in virtue of unjustified background beliefs. For example, suppose that Jenny reads about Walton's example at a young age before she has beliefs about the category PAINTING. Further, suppose that she gets the details wrong and mixes up PAINTING and GUERNICA. Over time she comes to gain lots of evidence that paradigm paintings have flat surfaces. Despite the accumulation of this evidence, she continues to believe that paradigm paintings have three dimensional surfaces (she is constantly disappointed that the museums she goes to are

33. To be clear, it's not plausible that these beliefs are the sole enrichment states. One could know about the paradigmatic surface features of paintings and not be in a position to perceive Guernica's violence. But it is plausible that these background beliefs are part of the set of states that ground the ability to perceive the aesthetic features of the painting.

34. Could this difference in perceiving the piece qua quernica and qua painting be explained in terms of different patterns of attention? And would this threaten the claim that the perceptual experience is enriched with high-level content in virtue of the background cognitive states? Although many take attention-based explanations to be a major threat to enrichment via cognitive penetration, Stokes $(2014 ; 2018 b ; 2018 a)$ shows that this is far from clear. Some attentional mechanisms are a threat to enrichment via cognitive penetration, but some are not. Further, it looks plausible that many aesthetic cases (including paradigm interpretations of Waltonian category cases) involve attentional variation that leads to cognitive penetration. So it looks like, at least some of the time, attentional shifts are part of the story, but this is not a threat to enrichment via cognitive penetration.

There is a separate question, raised by an editor for this journal, about whether attentional mechanisms can play the role of enrichment state even in cases where attention shifts explain away cognitive penetration. This would be an intriguing possibility as it would potentially neutralize the dialectical upshot of appeals to attentional shifts. In order to settle the question, more work would need to be done about how wide we should understand enrichment states. If we think of them in functional terms, then it seems like there will be some attentional shifts that will cause the manifestation of the functional state even though they themselves are not part of the functional state. If we take a wider view than this, though, then I see no principled reason why these attentional mechanisms will be ruled out as enrichment states. 
devoid of any paradigmatic paintings). She happens to be in Madrid and comes upon Guernica. She perceives it as serene. ${ }^{35}$ This perception is non-veridical. It is not a serene painting. Further, it's plausible that Jenny's perceptual experience of serenity lacks (full) rational power in virtue of her lack of justification to believe that paradigm paintings have three-dimensional surfaces. Thus, it is plausible that any justification it does provide is dependent on the justification she has for the background beliefs that partly constitute the Enrichment State.

This, of course, is an interesting and important result. It is not of central interest here, though. ${ }^{36}$ This is primarily because it is not plausible that all cases of enriched content are like this. This is because it is not plausible that all cases of enriched content involve enrichment states that are beliefs (or other rationally evaluable states). Sometimes the Enrichment State is a mere recognitional capacity. Recognitional capacities do not have justificatory statuses. Therefore, they are not the right sort of thing to ground the sort of epistemic dependence that spoils foundational justification. ${ }^{37}$

Given this, I will focus on the other aspect of enrichment. The key question is whether the rational power of the experience of enriched features depends on the rational power of the experience of the corresponding features. ${ }^{38}$ I think the answer is Yes. To begin to see why, notice that it looks like one loses ex ante justification to believe the high-level contents when one loses ex ante justification to believe the corresponding feature contents.

Imagine that you look at Olympia and experience both intensity and the lowlevel features that account for the facial expressions of the two women and the relations between those expressions. The Enrichment Account maintains that your representation of the intensity is parasitic on your representation of the corresponding features. Now suppose you learn that you were just slipped a

35. This example is far-fetched and unrealistic in a host of ways. However, the central phenomenon is ubiquitous. There are a vast amount of categories and many people are ignorant of their paradigmatic features. This leads to a lot of non-veridical perceptions. To use a different example, those who know a lot about the category PULP FICTION will perceive certain acts of gratuitous violence as funny, whereas those who don't know about that category and categorize the fiction in some more generic category might perceive the violence as disturbing. Someone is wrong (probably the former) and it is due to erroneous background beliefs about category. Further, it is plausible that this mistake affects the justification provided by the perception.

36. This sort of cognitive penetration is also a main theme in Wollheim (1982). There Wollheim makes it clear how important one's cognitive stock is to aesthetic perception, and uses this to complicate the dialectic about so-called formalism (what Wollheim calls the Scrutiny Thesis). Arguably Walton himself showed as much in 'Categories of Art'.

37. This is a general point about enriched content. It might be that enriched aesthetic content is not like this. This would mean that no version of formalism is correct. I rather doubt that but won't get into it here. The more general point is sufficient motivation to investigate the epistemic consequences of the other part of the mechanics of enriched content.

38. This question has, to my knowledge, not been explicitly discussed in the literature. Silins (2013) comes closest. 
drug that adversely affects your ability to accurately represent facial expressions. This plausibly defeats your (ex ante) justification for various beliefs about the corresponding features. And once you lose this ex ante justification, you also seem to lose your ex ante justification for believing that the painting is intense. Thus, it looks like the justification you get for the aesthetic content is dependent on the justification to believe claims about the corresponding features. Thus, it looks like your justification to believe that the painting is intense is not foundational.

To be clear, I am not claiming that one needs to have ex post justified beliefs about the facial expressions in order to be ex ante justified in believing the painting is intense. That would require too much. We often don't form beliefs about the corresponding features (at least not right away) even though we do form aesthetic beliefs. This is compatible with my claims. My claim is just that in order to be $e x$ ante justified to believe the aesthetic content one needs to be ex ante justified to believe the claims about corresponding features.

One might object to this argument by claiming that justificatory dependence does not always prevent experiences from providing foundational justification. For example, if you come to possess a sufficient reason to believe that your vision is unreliable, then token visual experiences will fail to provide ex ante justification. However, this doesn't mean that token experiences never provide foundational justification. ${ }^{39}$ When you lack reason to think you are unreliable, token experiences (of low-level content) can provide foundational justification. Nevertheless, there is some kind of dependence between this justification and not being justified in believing one is unreliable.

While I agree with this, I don't think this is the only sort of dependence involved with enriched content. The dependence involved with enriched content is positive dependence. The difference is that when it comes to general reliability, one needn't always have sufficient reason to believe one's vision is reliable in order for token experiences to provide justification, whereas in the case of enriched content, one does need to have sufficient reason to believe the corresponding feature content in order to be ex ante justified to believe the enriched content. When it comes to general reliability, the justification provided by token experiences is dependent on lack of justification for the claim that one is unreliable. When it comes to enriched content, the justification for token instances of enriched content is dependent on having justification to believe the corresponding feature content.

Thus, something stronger is needed in the enriched content case than in the general reliability case. Challenges to one's reliability can defeat the power of token experiences but that doesn't mean one always needs positive reasons to believe one is reliable in order for token experiences to justify. Merely lacking a

39. This is actually very controversial. Wright (2002) and Cohen (2002) argue that this does in fact spoil foundational justification. Silins (2013) and Pryor (2013) disagree. I side with Silins and Pryor. 
challenge to one's reliability is enough to get justification from token experiences. But merely lacking a challenge to corresponding feature content is not enough. One needs to have positive justification-justification that is usually provided by the experience itself-to believe the corresponding feature content in order for the experience of the high-level features to provide justification. The key point is that negative dependence does not spoil foundational justification but positive dependence does. Thus, the justification we get for enriched content is not foundational..$^{\circ}$

The important upshot is this: The justification one gets from an aesthetic perception is dependent on one's justification to believe that the object has various features that indicate or ground the aesthetic features. Thus, the structure of one's justification is non-foundational. It thus shares something importantly in common with the structure of ordinary non-foundational inferential justification.

\section{Aesthetic Perception and the Rationality of Criticism}

With the Enrichment Account and its epistemic consequences on the table, we can dissolve our motivating tension. There is no tension between the Enrichment View and the idea that criticism is a rational practice. Indeed, the Enrichment View predicts that one can provide justification for enriched content by appealing to the corresponding features the perception of which enables enrichment. This is exactly what critics do. Thus, the Enrichment View seems tailor made to account for the rational merit of critical arguments.

To fully appreciate the dissolution, focus again on Olympia and its intensity. Suppose Alexander sees the painting and comes to rationally believe that it is intense. The Enrichment View maintains that Alexander is justified via perception. However, this justification is not foundational. Instead, the justificatory power of his perception of the intensity is dependent on his ex ante justification for believing certain claims about Olympia's corresponding features (in my analysis this has to do with the facial expressions and their relations). To be clear, the Enrichment View does not predict that Alexander infers that the painting is intense from the claims about the corresponding features. It doesn't even require that Alexander believe the claims about the corresponding features. It does maintain, though, that Alexander be ex ante justified to believe those claims. This justification is provided

40. In Lord (2019) I argue for something even stronger. Namely, that the justification one gets for high-level content is inherited from the justification we get from corresponding feature content. We can see this most clearly by noticing that we lose our justification to believe the high-level content when the justificatory link between the low-level content and the high-level content is severed. Here I don't need this stronger claim since I am merely interested in showing that the justification is not foundational. Showing that it is positively dependent is enough to show this. 
by his perceptual experience of the features. ${ }^{41}$

Now suppose Alexander is a critic and he sets out to critically engage with Olympia. He claims the painting is intense in virtue of the facial expressions of the women and their relations. According to the view defended in the last section, to cite these claims is to appeal to features that Alexander's perceptual justification depends upon. Thus, the Enrichment View predicts that by citing these features Alexander is elucidating his justification for believing that the painting is intense. Critical arguments thus have rational merit according to the Enrichment View.

So that's one side of the tension. Does this explanation spoil perception's central role in aesthetic thought? No. The Enrichment View is compatible with thinking that perception is required for rational aesthetic judgment. Indeed, the Enrichment View goes a long way to vindicating this by explaining how aesthetic perception is possible in the first place. The key point is that even if perception is required for rational aesthetic judgment, the Enrichment View can explain why critical arguments have rational merit.

It must be stressed, however, that much like Hopkins's (2007b) account, the pure perceptualist version of the Enrichment view maintains that the justification provided by the critical argument is asymmetric. It is only available to the critic. The consumer cannot come to be justified in the conclusion by inferring the conclusion from the premise..$^{2}$

Given this, one might legitimately wonder what the point of such an activity is if consumers of criticism cannot gain rational judgments by engaging with criticism. This is where the idea of perceptual guidance comes back to the fore. The Enrichment View elegantly explains perceptual guidance. If the Enrichment View is true, then one needs to experience low-level features in the right way in order to perceive the aesthetic features. When all goes well, one ends up with justified judgments that are epistemically dependent on ex ante justification to believe the corresponding feature contents. By pointing out the corresponding features in just the right way, the critic both elucidates the structure of her justification and points the consumer towards the features one needs to process in order to see the aesthetic features for oneself. This, I contend, is exactly the sort of 'perceptual proof' that criticism seems to wear on its sleeve.

One might think that this does not fully vindicate the value of critical arguments. It might well be true that critical arguments can guide perception, but one might wonder whether there is some connection between such guidance and

41. This shows that even though one doesn't get foundational justification for aesthetic claims via aesthetic perception, we don't need to worry too much about a regress of justification. This is because the chain of justification will end in perceptual experiences of low-level content.

42. At the end of the day, I would like to deny that the justification is asymetric. That is, I would like to argue that the consumer can get justification from critical arguments. My main concern in this paper, however, is to show that the Enrichment View can resolve the tension between the critical arguments having rational merit and pure perceptualism. 
their status as arguments (or elucidations of reasons). I think it is helpful here to lean on Cross (2017). Cross's basic idea (following up on Ziff 1966) is that critical arguments provide practical reasons. They do this by presenting arguments that recommend engaging with works in particular ways. Alexander gives you reasons to look at Olympia in certain ways by pointing you towards the facial features and their relations.

It is worth pausing for a moment to further consider Cross's view. It is right, I think, that part of what critics do in the process of providing perceptual guidance is provide practical reasons to engage with the work in various ways. Indeed, they might also provide instructions for acquiring enrichment states in the first place (e.g., by providing you information about Waltonian categorical facts).

Cross flirts with inferring that critical arguments are only practical. This, I think, is a mistake. One reason why is that we need an explanation of the striking fact that the features it makes sense to recommend one pay attention to are precisely the features that justify the critic, on my account. The reason, I think, is that those are the features the aesthetic features depend upon. They are thus what you'd expect the critics' justification to depend upon (as my account predicts) and the features you'd expect one to have practical reasons to engage with. Given that my view can explain all of these things, there is no need to follow Cross in thinking that critical arguments are only practical. They serve a practical function and Cross is right to think that this is part of the vindication of critical arguments. But this is not all they do. They also elucidate the structure of the justification critics have for their conclusions. It is not accident, given my account, that this is so. 43

The final virtue of the Enrichment Account is that it provides the resources for an interesting view about the nature of taste. According to this account, taste is at least partly a matter of having certain kinds of perceptual expertise. This perceptual expertise is constituted by (or, at the very least, related to) the enrichment states, which dispose one to perceive the aesthetic features of things. The fact that the perceptual abilities these states provide are not automatic explains why aesthetic perception is unlike ordinary perception. It also explains why one

43. There are other issues with thinking that critical arguments are only practical. For one, this doesn't really do justice to the structure of the arguments. Very often the text leads up to a evaluative conclusion. This seems like a bona fide conclusion, one that it is rationally connected to the characterization provided by the text. This structure-the structure that holds between the conclusion and the characterization-is not plausibly understood solely in terms of practical reasons (Hopkins 2007b makes a similar point). It's not even clear what that would mean. For example, Fried claims that Caravaggio is visionary because his paintings represent both the immersive and specular relation. He then points to features that such representations depend upon. It is plausible that this provides viewers with practical reasons to pay attention to the features that those representations depend upon. But what about the relation between Fried's conclusion and the facts on the right side of the 'because'? It is not plausible that that relation is merely practical. 
needs taste in order to perceive the aesthetic. It is because one's taste is constituted by one's perceptual expertise.

\section{Concluding by Comparing}

It is worth ending by comparing my view to Sibley's, Dorsch's, and Hopkins's views. It is easy to see the difference between Sibley's view and mine. According to Sibley, successful critical arguments elucidate both why the object is the way it is aesthetically and why the critic judges that the object is that way. However, such arguments do not present the critic's justification for so judging. My view denies this last step. It holds that such arguments do present the critic's justification. This is because her perceptual justification is dependent upon the premises cited.

That said, the pure perceptualist version of the Enrichment View agrees with Sibley that consumers cannot get justification from critical arguments. The Enrichment View can explain why not. While the justification of the critic is nonfoundational, it is still perceptual. Since the critic cannot transmit her perceptual justification via testimony, the consumer is not in a position to receive the critic's justification. ${ }^{44}$

To blunt the awkwardness of this asymmetry, the pure perceptualist version of the Enrichment View agrees again with Sibley that critical arguments can benefit the consumer by guiding perception. And, once again, the Enrichment View provides an excellent explanation of how this works. Successful critical arguments explicate the corresponding features that the aesthetic features depend upon. They thus pick out the features one needs to process in order to perceive the aesthetic features, according to the Enrichment View. Critical arguments (or successful ones) thus provide a literal guide for making the aesthetic perceptible. By supplementing this Sibelyian story with Cross (2017), we get the conclusion that in addition to elucidating the structure of the critic's justification, critical arguments also provide practical reasons to engage with works in certain ways; this is part of perceptual guidance.

Now let's turn to Dorsch. It takes more work to clearly distinguish my view from Dorsch's. Ultimately I think the difference is that Dorsch holds that aesthetic justification is inferential in every epistemically relevant way. That is, he thinks

44. There is a gap here. To see it, suppose that Christy, a top climate scientist, learns some complicated fact $p$ from a complicated experiment she just ran. Now suppose that she tells Donnie, her student, $p$. Donnie might not be sophisticated enough to justifiably believe $p$ on the basis of the experiment. Still, Donnie is justified to believe $p$ simply on the basis of Christy's testimony. Thus, the unavailability of a testifier's method does not mean that justified belief in the conclusion is unavailable. This is true but not squarely on point here. The issue right now is whether the justification provided by the critical argument is available to the consumer. It's a separate issue whether the consumer is justified in believing the conclusion of the argument on the basis of testimony. 
that aesthetic justification is on all fours with ordinary inferential justification. This means not only that aesthetic ex ante justification is non-foundational, but also that ex post aesthetic justification is inferential. This is why he thinks his view spells doom for traditional versions of perceptualism.

I, on the other hand, do not think that the Enrichment View is a threat to perceptualism. While it is the case that the ex ante justification provided by aesthetic perceptions is non-foundational, it is not the case that ex post aesthetic justification is inferential, at least not in the epistemically relevant sense of inference. Dorsch seems to think that since the ex ante justification is non-foundational, it must also be the case that critics infer their judgments from judgments about the corresponding features, at least implicitly. I deny that this is a good inference. Non-foundational ex ante justification does not necessitate inferential ex post justification.

Why? As I argue elsewhere at greater length, the key is noticing that even if one's ex ante justification is non-foundational, one still gets perceptual access to enriched content. ${ }^{45}$ In other words, the enriched content is made manifest in a perceptual way. This means that the aesthetic content is presented in the experience for the taking. This allows one to come to non-inferentially judge the aesthetic content on the basis of the experience. This process is epistemically different than inferential processes. It is the process involved in paradigmatic perceptual justification. Thus, the perceptualist who endorses the Enrichment View can maintain that aesthetic justification is perceptual even though it is nonfoundational. This is what allows her to account for the asymmetric rational merit of critical arguments. This is exactly what is needed to chart the middle path between Sibley and Dorsch.

Now, to finish, let's consider Hopkins's view. Hopkins's view, unlike Dorsch's, is compatible with the transition from perception to judgement being noninferential. However, the key innovation in Hopkins's view is the claim that the perceptual experience of aesthetic features is itself inferred. One way to understand this claim is to hold that the perceptual experience of the aesthetic features is itself inferred from the perceptual experiences of the corresponding features.

Hopkins's view, then, can be understood as a version of the Enrichment View. It is a specific version insofar as it takes a very precise position about the nature of the enrichment process: It's inference. The key point to appreciate is that we don't need to adopt this view in order for their to be non-foundational justification. On my view, the justification provided for enriched high-level content is non-foundational no matter what the process is like. The epistemic dependence is independent of the mechanics of the process. This is a virtue, for it allows us to avoid making controversial—and I think ultimately implausible-claims about

45. See Lord (2019) for the longer defense. 
the role of inference in the etiology of perceptual experience.

Thus, it looks the view defended here has all of the main virtues of the competing views without any of their main vices. Like Dorsch's and Hopkins's views, it explains the rational merit of critical practice. But, like Sibley's and Hopkins's views, it holds on to perceptualism. Like Sibley's view, it accommodates perceptual guidance; indeed, it provides an elegant explanation of how perceptual guidance actually works. Finally, it does all of this without resorting to controversial and ultimately implausible claims about inference, which is the main advantage it has over Hopkins's view and one of the main advantages it has over Dorsch's view. Thus, the view looks comparatively very plausible. When we add the fact that the main resources of the account are mined from fully general and plausible views about the metaphysics and epistemology of perception, we can see that it is also very plausible in absolute terms.

\section{Acknowledgments}

Thanks to audiences at the 2018 annual meetings of both the American and European Societies of Aesthetics, the FRIAS Workshop on Normative Epistemology, the Higher Seminar on Aesthetics at the University of Uppsala, the University of Munich, the University of Helsinki, the University of Stockholm, Lund University, the University of Hamburg, the Metaethics Workshop at the Frankfurt School of Finance and Management, the London Aesthetics Forum, and The Future of Normativity Conference at the University of Kent. Thanks especially to Paloma Atencia Linares, Servaas van der Berg, Elisabeth Schellekens, David Davies, Paulina Sliwa, Rob Hopkins, Daniel Star, and Andrew Huddleston. The research leading to these results has received funding from the People Programme (Marie Curie Actions) of the European Union's Seventh Framework Programme (FP7/ 2007-2013) under REA grant agreement $n^{\circ}$ [609305]. Research on this project was also supported by the Freiburg Institute for Advanced Study (FRIAS), University of Freiburg, Germany.

\section{References}

Audi, Robert (2013). Moral Perception. Princeton University Press.

Binkley, Timothy (1977). Piece: Contra Aesthetics. Journal of Aesthetics and Art Criticism, 35(3), 265-277.

Byrne, Alex and Susanna Siegel (2017). Rich or Thin? In Bence Nanay (Ed.),

Current Controversies in Philosophy of Perception (59-80). Routledge.

Carroll, Noël (2001). Beyond Aesthetics: Philosophical Essays. Cambridge University Press. 
Carroll, Noël (2008). On Criticism. Routledge.

Cavedon-Taylor, Dan (2017). Reasoned and Unreasoned Judgement: On Inference, Acquaintance and Aesthetic Normativity. British Journal of Aesthetics, 57(1), 117. https: / / doi.org/10.1093/aesthj/aywo88

Cohen, Stewart (2002). Basic Knowledge and the Problem of Easy Knowledge. Philosophy and Phenomenological Research, 65(2), 309-329.

Connolly, Kevin (2014). Perceptual Learning and the Contents of Perception. Erkenntnis, 79(6), 1407-1418.

Cross, Anthony (2017). Art Criticism as Practical Reasoning. British Journal of Aesthetics, 57(3), 299-317.

Currie, Gregory (1990). Supervenience, Essentialism and Aesthetic Properties. Philosophical Studies, 58(3), 243-257.

Dorsch, Fabian (2013). NonInferentialism about Justification - The Case of Aesthetic Judgements. Philosophical Quarterly, 63(253), 660-682.

Fried, Michael (2010). The Moment of Caravaggio. Princeton University Press.

Gorodeisky, Keren (2010). A New Look at Kant's View of Aesthetic Testimony. British Journal of Aesthetics, 50(1), 53-70.

Gorodeisky, Keren and Eric Marcus (2018). Aesthetic Rationality. Journal of Philosophy, 115(3), 113-140.

Grant, James (2013). The Critical Imagination. Oxford University Press.

Hampshire, Stuart (1954). Logic and Appreciation. In William Elton (Ed.), Aesthetics and Language (161-169). Blackwell.

Helton, Grace (2016). Recent Issues in High-Level Perception. Philosophy Compass, 11(12), 851-862.

Hopkins, Robert (2007a). Critical Reasoning and Critical Perception. In Matthew Kieran and Dominic McIver Lopes (Eds.), Knowing Art (137-153). Springer.

Hopkins, Robert (2007b). What Is Wrong with Moral Testimony? Philosophy and Phenomenological Research, 74(3), 611-634.

Huemer, Michael (2001). Skepticism and the Veil of Perception. Rowman \& Littlefield. Isenberg, Arnold (1949). Critical Communication. Philosophical Review, 58(4), 330344.

Johnston, Mark (2006). Better Than Mere Knowledge? The Function of Sensory Awareness. In John Hawthorne and Tamar Gendler (Eds.), Perceptual Experience (260-290). Oxford University Press.

Kant, Immanuel (200o). Critique of the Power of Judgment. Paul Guyer and Eric Matthews (Eds.). Cambridge University Press.

Lamarque, Peter (2010). Work and Object: Explorations in the Metaphysics of Art. Oxford University Press.

Levinson, Jerrold (1980). Aesthetic Uniqueness. Journal of Aesthetics and Art Criticism, 38(4), 435-449.

Levinson, Jerrold (2001). Aesthetic Properties, Evaluative Force, and Differences 
of Sensibility. In Emily Brady and Jerrold Levinson (Eds.), Aesthetic Concepts: Essays After Sibley (61-80). Oxford University Press.

Lord, Errol (2016). On the Rational Power of Aesthetic Testimony. British Journal of Aesthetics, 56(1), 1-13.

Lord, Errol (2018a). How to Learn about Morality and Aesthetics through Acquaintance and Testimony. In Russ Shafer-Landau (Ed.), Oxford Studies in Metaethics (Vol. 13, 71-97). Oxford University Press.

Lord, Errol (2018b). The Importance of Being Rational. Oxford University Press.

Lord, Errol (2019). Enriched Content, the Limits of Foundationalism, and the Epistemic Powers of Perception. Manuscript in preparation.

Lord, Errol (in press). The Vices of Perception. Philosophy and Phenomenological Research.

Macpherson, Fiona (2011). Introduction: The Admissible Contents of Experience. In Katherine Hawley and Fiona Macpherson (Ed.), The Admissible Contents of Experience (1-15). Wiley-Blackwell.

McGrath, Matthew (2013). Phenomenal Conservatism and Cognitive Penetration: The Bad Basis Counterexamples. In Chris Tucker (Ed.), Seemings and Justification: New Essays on Dogmatism and Phenomenal Conservatism (225-247). Oxford University Press.

Nanay, Bence (2012). Perceptual Phenomenology. Philosophical Perspectives, 26(1), 235-246.

Nanay, Bence (2016). Aesthetics as Philosophy of Perception. Oxford University Press.

Nussbaum, Emily (2018, January 22). "High Maintenance": An Anthology Show that Really Works. The New Yorker.

Pryor, James (2000). The Skeptic and the Dogmatist. Noûs, 34(4), 517-549.

Pryor, James (2013). Problems for Credulism. In Chris Tucker (Ed.), Seemings and Justification: New Essays on Dogmatism and Phenomenal Conservatism (89-131). Oxford University Press.

Schellekens, Elisabeth (2006). Towards a Reasonable Objectivism for Aesthetic Judgements. British Journal of Aesthetics, 46(2), 163-177.

Schine, Cathleen (2012, October 11). Imaginary Friends. The New York Review of Books.

Shelley, James (2003). The Problem of Non-Perceptual Art. British Journal of Aesthetics, 43(4), 363-378.

Shelley, James (2007). Critical compatibilism. In Matthew Kieran and Dominic McIver Lopes (Eds.), Knowing Art (125-136). Springer.

Shelley, James (2017). The Concept of the Aesthetic. In Edward N. Zalta (Ed.), The Stanford Encyclopedia of Philosophy (Winter 2017 ed.). Retrieved from https://plato.stanford.edu/archives/win2017/entries/aesthetic-concept/

Sibley, Frank (1965). Aesthetic and Nonaesthetic. The Philosophical Review, 
74(2), 135-159.

Sibley, Frank (2001). Approach to Aesthetics: Collected Papers on Philosophical Aesthetics. Oxford University Press.

Siegel, Susanna (2006). Which Properties Are Represented in Perception? In Tamar S. Gendler and John Hawthorne (Eds.), Perceptual Experience (481-503). Oxford University Press.

Siegel, Susanna (2010). The Contents of Visual Experience. Oxford University Press. Siegel, Susanna (2012). Cognitive Penetrability and Perceptual Justification. Nô̂s, $46(2), 201-222$.

Siegel, Susanna (2017). The Rationality of Perception. Oxford University Press.

Silins, Nicholas (2013). The Significance of High-Level Content. Philosophical Studies, 162(1), 13-33.

Stokes, Dustin (2014). Cognitive Penetration and the Perception of Art (Winner of 2012 Dialectica Essay Prize). Dialectica, 68(1), 1-34.

Stokes, Dustin (2018a). Attention and the Cognitive Penetrability of Perception. Australasian Journal of Philosophy, 96(2), 303-318. https://doi.org/10.1080/ 00048402.2017.1332080

Stokes, Dustin (2018b). Rich Perceptual Content and Aesthetic Properties. In Anna Bergqvist and Robert Cowan (Eds.), Evaluative Perception (19-41). Oxford University Press.

Walton, Kendall L. (1970). Categories of Art. Philosophical Review, 79(3), 334-367. Wollheim, Richard (1982). Art, Interpretation, and Perception. In The Mind and its Depths (132-143). Harvard University Press.

Wright, Crispin (2002). (Anti-)Sceptics Simple and Subtle: G. E. Moore and John McDowell. Philosophy and Phenomenological Research, 65(2), 330-348.

Ziff, Paul (1966). Reasons in Art Criticism. In Philosophic Turnings (47-74). Cornell University Press. 